\title{
Crisis del capitalismo global. Desarrollo y medio ambiente
}

\author{
Leandro del Moral Ituarte \\ Universidad de Sevilla. Departamento de Geografía Humana \\ lmoral@us.es
}

\begin{abstract}
Resumen
Sobre la base de una larga tradición de estudios acerca de la relación de la humanidad con la naturaleza, el agravamiento de los conflictos ambientales está provocando la intensificación y la renovación del debate en el contexto de la actual crisis sistémica. La escasez, el encarecimiento o el agotamiento de recursos no renovables y renovables se interpreta de diferentes maneras en el marco de distintas aproximaciones a la dialéctica sobre la naturaleza y la sociedad, así como en el marco de valoraciones contrapuestas del sistema capitalista. Con este telón de fondo, en el presente artículo, se analiza la relación entre el deterioro por causas antrópicas del medio físico y los procesos socioeconómicos en curso y de largo plazo. ¿De qué naturaleza, de qué medio ambiente estamos hablando? ¿Existe en realidad una dependencia fundamental de las dinámicas socioeconómicas respecto del medio ambiente? ¿En qué escalas temporales y con qué diferenciaciones espaciales se producen dichas relaciones? Estas son algunas de las preguntas que estructuran el artículo.
\end{abstract}

Palabras clave: crisis sistémica; declive de la sociedad industrial; ecologías del miedo; decrecimiento; polarización; desigualdad.

\section{Resum. Crisi del capitalisme global, desenvolupament $i$ medi ambient}

Sobre la base d'una llarga tradició d'estudis sobre la relació de la humanitat amb la natura, l'agreujament dels conflictes ambientals està provocant la intensificació i la renovació del debat en el context de la crisi sistèmica actual. L'escassetat, l'encariment o l'esgotament de recursos no renovables i renovables s'interpreta de maneres diferents en el marc d'aproximacions diverses a la dialèctica entre natura i societat i de valoracions contraposades del sistema capitalista. Amb aquest teló de fons, en el present article, s'analitza la relació entre el deteriorament per causes antròpiques del medi físic i els processos socioeconòmics en curs i de llarg termini. De quina naturalesa, de quin medi ambient estem parlant? Existeix en realitat una dependència fonamental de les dinàmiques socioeconòmiques respecte del medi ambient? En quines escales temporals i amb quines diferenciacions espacials es produeixen les esmetades relacions? Aquestes són algunes de les preguntes que estructuren l'article.

Paraules clau: crisi sistèmica; declivi de la societat industrial; ecologies de la por; decreixement; polarització; desigualtat. 
Résumé. Crise du capitalisme, développement et environnement

Basé sur une longue tradition d'études sur la relation de l'humanité avec la nature, l'aggravation des conflits environnementaux sont à l'origine de l'escalade et le renouvellement du débat, dans le contexte de la crise systémique actuelle. Les pénuries, les plus élevés ou l'épuisement des ressources non renouvelables et renouvelables est interprété de différentes manières selon des approches différentes à la nature-société dialectique et évaluations contradictoires du système capitaliste. Dans ce contexte, cet article examine la relation entre la détérioration des causes anthropiques des processus physiques et socio-économique en cours et à long terme. De quelle nature, ce que l'environnement parlons-nous? Vraiment la situation socio-économique sont profondément conditionnées par l'environnement? Qu'est-ce échelles temporelles et spatiales de ces interactions se produisent? Voici quelques questions que la structure de l'article

Mots clé: crise systémique; déclin de la société industrielle; écologie de la peur; décroissance; polarisation; inégalité.

\section{Abstract. The Crisis of Global Capitalism: Development and the Environment}

On the basis of a long tradition of studies about the relationship of humanity to the natural environment, the worsening of environmental conflicts is leading to the intensification and renewal of the debate in the context of the current systemic crisis. The shortage, escalating costs and depletion of non-renewable and renewable resources is interpreted in different ways under different approaches to the nature-society dialectic and the contradictory assessments of the capitalist system. Against this background, this paper examines the debate on the relationship between human causes for environmental deterioration and ongoing and long-term socioeconomic processes. Of what nature and of what environment are we speaking? Do socioeconomic dynamics truly depend on the environment? Under which time scales and spatial differentiations do these relationships occur? These are some of the questions that structure this text.

Keywords: systemic crisis; decline of industrial society; ecologies of fear; de-growth; polarization; inequality.

\section{Sumario}

Introducción El debate sobre el decrecimiento

Advertencias de catástrofe

Críticas de las «ecologías del miedo» y énfasis en la acción política

La distribución espacialmente desigual de los impactos del metabolismo social
Críticas a las propuestas decrecentistas

Dificultad de las alternativas

Consideraciones finales

Bibliografía 


\section{Introducción}

El debate sobre los límites del crecimiento y la crítica del concepto de «desarrollo sostenible» ha experimentado una gran intensificación en los últimos años. El debate actual se apoya en una potente elaboración previa, de la que los trabajos de Kenneth Boulding (The Economics of Coming Spaceship Earth), Nicholas Georgescu-Roegen (La dégradation entropique et la destinée prométhéenne de la technologie humaine), Herman Daly (Beyond Growth: The Economics of Sustainable Development), André Gorz (Capitalisme, Socialisme, Ecologie), Ernst Friedrich Schumacher (Small is Beautiful) o el Informe Meadows de 1972 (The Limits to growth), con sus coincidencias y discrepancias entre ellos, constituyen eslabones fundamentales.

Entre los puntos de referencia de esta larga reflexión, es inexcusable situar el histórico simposio Man's Role in Changing the face of the Earth, celebrado en 1955 en Princeton. Este seminario, promovido por Carl O. Sauer, Lewis Mumford y Clarence Glacken, constituyó un hito en el estudio sobre el papel del hombre en la transformación de la superficie terrestre. Paradójicamente, su mensaje central - la importancia de la relación entre la humanidad y el medio ambiente como un tema central de estudio - fue ignorado, si no rechazado, por la geografía durante las décadas posteriores. Treinta años más tarde, en 1987, se celebró otro simposio en la Clark University dedicado a The Earth as Transformed by Human Action, con objetivos similares al de 1955 y, como aquel, organizado por geógrafos, pero con un carácter decididamente interdisciplinario (Capel, 2003).

Contribuyendo a las cuestiones clave de este debate, destacan, entre los autores españoles, los trabajos (y las intervenciones en acciones político-sociales) de José Manuel Naredo (Raices económicas del deterioro ecológico y social. Más allá de los dogmas), Antonio Estevan (Hacia la reconversión ecológica del transporte en España 1996, Herencias y problemas de la política hidráulica española 2008), Jorge Riechmann (Gente que no quiere viajar a Marte. Ensayos sobre ecología, ética y autolimitación) y Joan Martínez Alier (De la Economía Ecológica al Ecologismo Popular).

La actual eclosión de la demanda de rigor en el análisis de los procesos de desarrollo procede de una larga maduración, con profundas raíces en la reflexión representada por los autores citados. Esta nueva demanda de rigor se produce, además, paralelamente a la penetración del debate en nuevos sectores significativos de agentes sociales (organizaciones políticas, ciudadanas, sindicales). Lo que hasta hace muy poco era un discurso con dos dimensiones (un foco académico-intelectual, respetado pero minoritario, por un lado, y un discurso «ecologista», con repercusión mediática, pero trivializado o marginalizado, por otro), encuentra cierto eco en ámbitos más amplios y relativamente más representativos de la diversidad social. La necesidad de combatir la retórica ambiental, la demanda de profundidad en los análisis - concretada en indicadores sobre materia, energía, metabolismo y huella ecológica, pero también sobre participación activa real, cohesión, inclusión social y paisajes - también 
ha calado en el debate geográfico. Esta disciplina cuenta con experiencias de reflexión teórica e investigación empírica, como la que representa el trabajo de Juan Ojeda Rivera (Ojeda, 1999, 2011) o los debates y los trabajos del equipo del Informe de Desarrollo Territorial de Andalucía (IDTA) (Zoido, 2001; Caravaca y Zoido, 2006; Pita y Pedregal, 2011).

Es cierto que, casi coincidiendo con la emergencia de esta reactivación del pensamiento crítico sobre el desarrollo, la crisis mundial desencadenada a partir de 2008, y especialmente prolongada y profunda en los países ricos (Europa, EEUU), ha generado nuevas prioridades (desempleo masivo, desmantelamiento del estado de bienestar, desahucios, extensión de la pobreza, etc.). Estas nuevas prioridades han generado la obsesión por la necesidad de reactivar el crecimiento, incluso medido con los parámetros convencionales como el producto interior bruto (PIB), ya largamente puestos en cuestión. La reacción frente a la crisis y sus consecuencias ha hecho aflorar, con resistencias por parte de las doctrinas neoliberales hegemónicas, planteamientos que ponen como prioridad la inversión pública, la reactivación económica y el crecimiento. Se trata de planteamientos como los que representan los premios Nobel de Economía Paul Krugmann (Krugmann, 2009) y Joseph Stiglitz (Griffith-Jones et al., 2010) y en España, por ejemplo, Juan Torres y Vicenç Navarro (Navarro et al., 2011). Estos autores no ignoran, por supuesto, las necesidades de un nuevo modelo de desarrollo (modelo energético alternativo, yacimientos de empleos verdes, etc.), pero el núcleo de su pensamiento y sus propuestas prioritarias se sitúan en la lógica del crecimiento económico convencional.

Sin embargo, hoy es una opinión poco incontrovertida que, en los países ricos occidentales, las nuevas generaciones vivirán peor que sus padres. Desde hace alrededor de veinte años, el peso de las rentas salariales en el conjunto de la renta disponible experimenta una tendencia descendente, pese al aumento de la población asalariada. Los países centrales están «decreciendo» profunda y desordenadamente. Ese es el significado del concepto de recesión. Un deterioro de las condiciones laborales, de las rentas, del acceso a los bienes y servicios que no se distribuye homogéneamente, ni en términos espaciales ni sociales, entre la población, sino que se acompaña de un aumento de la desigualdad, categoría de creciente importancia en el mundo actual. Acumulación de riqueza, de un lado, y precarización de las condiciones de vida, de otro, es decir polarización.

Pero, ¿está significando la crisis una disminución de las presiones sobre los ecosistemas y recursos naturales? ¿Están mejorando las condiciones del medio ambiente? O, por el contrario, ¿son los cambios hacia el deterioro (cambios entrópicos) de este medio físico los factores explicativos fundamentales de los procesos en curso y las tendencias estructurales de largo plazo? :Existe en realidad una dependencia fundamental de las dinámicas socioeconómicas respecto del entorno físico? ¿Podrá sobrevivir la humanidad en buenas condiciones de vida pese al deterioro de los ecosistemas? ¿¿De qué naturaleza, de qué medio ambiente estamos hablando?

Estas preguntas no son retóricas, porque existe una gran controversia en las ciencias físico-naturales y en las ciencias sociales sobre las respuestas a ellas. 


\section{Advertencias de catástrofe}

Toda la corriente de pensamiento anteriormente citada considera que el crecimiento exponencial que la humanidad ha conocido desde la incorporación de las energías fósiles hasta el metabolismo social será un fenómeno transitorio de la historia humana que toca a su fin. Somos la única especie hasta ahora que ha superado (artificialmente) los límites ecológicos (Georgescu-Roegen, 1977; Naredo, 2007; citados por Fernández Durán, 2011: 94). En eso consiste precisamente, se podría replicar, la característica de la especie humana: en superponerse a sus límites físico-naturales. Pero esta forma de actuar, en el contexto histórico de la civilización industrial (desde la primera revolución industrial definida por la difusión de la máquina de vapor), se materializa en un metabolismo apoyado básicamente «en la extracción de rocas y minerales de la corteza terrestre, en vez de en los derivados de la fotosíntesis, como hace el resto de las especies de la biosfera y como había hecho la especie humana a lo largo de su historia" (Naredo y Valero, 1999: 21). Y este metabolismo de la sociedad industrial arrastra hacia un creciente deterioro de la base de recursos planetarios, acompañado de una creciente polarización social y territorial. En los trabajos de José Manuel Naredo y Antonio Valero sobre la evolución de la corteza terrestre, el agua y la atmósfera, así como sobre la composición del estado de máxima entropía hacia la que tiende nuestro planeta, se señala expresivamente que «la vida surgió y evolucionó en la Tierra a partir, como se dice, de una "sopa primigenia", la civilización industrial la está empujando hacia una especie de "puré póstumo" en el que estarían revueltos todos los materiales que la componen" (Naredo, 2011: 27).

Ahora bien, desde una perspectiva práctico-política, es importante considerar la escala espacial y temporal en la que este "colapso entrópico» se puede producir. En ese sentido, la siguiente opinión de Robert Solow expresa una categoría que subyace sin expresarse en el «sentido común» colectivo cuando ignora las consecuencias (¡a qué plazo?) del deterioro de la base físico-natural de la vida social. Preguntado «sobre si, en su opinión, las transformaciones materiales que precisa la actividad económica se encuentran limitadas por la ley de la entropía», respondió reconociendo que "no cabe duda que todo está sometido a la ley de la entropía», pero precisó que «tal cosa no es de importancia práctica inmediata para modelizar lo que en último término es un breve instante de tiempo en una pequeña esquina del universo" (Naredo y Valero, 1999: 25). El problema es que, en esta respuesta, Solow identifica la ley de la entropía con la remota muerte caliente final del Universo, pero esta ley tiene implicaciones más inmediatas y relevantes del siguiente tipo: no se puede quemar dos veces el mismo trozo de carbón. Cuando se quema, se obtiene calor útil pero también hollín, cenizas, $\mathrm{CO}_{2} \mathrm{y}$ calor inútil; existen limitaciones a la eficiencia de la conversión de una a otra forma de energía o límites prácticos al reciclaje de materiales (Daly, 1999: 23).

Hace más de diez años, Ulrich Beck, aunque desde otra perspectiva, como veremos más adelante, escribía que las «pautas colectivas de vida, progreso y 
capacidad de control, pleno empleo y explotación de la naturaleza típicas de la primera modernidad han quedado socavadas por cinco procesos interrelacionados: la globalización, la individualización, la revolución de los géneros, el subempleo y los riesgos globales (como la crisis ecológica y el colapso de los mercados financieros globales). El auténtico reto teórico y político de la segunda modernidad es el hecho de que la sociedad debe responder simultáneamente a todos estos desafíos» (Beck, 2002 (1999): 2).

De resulta de este panorama general, un número cada vez mayor de hombres y mujeres se ven obligados a considerar el futuro como una amenaza, y no como un refugio o una tierra de promisión. En todo el mundo, de una manera simultánea, el «trabajo frágil» aumenta con rapidez, es decir, el trabajo a tiempo parcial, por cuenta propia, los contratos eventuales y otras formas de trabajo para las que apenas hemos encontrado descripciones adecuadas. Ya en 1999, Ulrich Beck advertía que si esa dinámica proseguía, en diez o quince años (es decir, entre 2009 y 2014), cerca de la mitad de la población activa de Occidente trabajaría en condiciones de incertidumbre. Ciertamente, no se puede decir que Beck, que escribía en pleno boom de las "punto com", se haya equivocado. Lo que solía ser una excepción se estaba convirtiendo, ya hace más de diez años, en una regla que implica que no hay más margen de maniobra que el de elegir entre: $a$ ) la protección social del creciente número de pobres, a costa de un elevado desempleo y $b$ ) aceptar la pobreza de amplios sectores de la población, para alcanzar un índice de desempleo ligeramente inferior. «La incertidumbre endémica es lo que va a caracterizar la existencia básica de la mayoría de las personas - incluyendo las clases medias aparentemente acomodadas - en los años venideros» (ibídem: 16-19).

Algunos autores describen esta perspectiva de manera muy gráfica y concreta. Según Ramón Fernández Durán, en los países centrales, las generaciones que van a vivir plenamente los escenarios de crisis profundas de las próximas dos décadas (2010-2030) son un abanico de cohortes de edad situadas entre la generación del 68, que abandona ya poco a poco su ciclo de vida laboral (mercantil) y la llamada "generación más preparada de la historia». La primera, que es la que ha vivido en la opulencia del petróleo, puede llegar al final de su ciclo vital en una situación de penuria, pero, en general, parte de una buena base, pues muchos de ellos son propietarios de su vivienda o tienen un alquiler seguro y en ocasiones hasta social, además de estar todavía atendidos por el Estado social. Pero las dos siguientes generaciones, la que puede estar ahora en los $40-50$ y la que está en la actualidad en los 20-30 años, llevarán sobre sus espaldas el grueso del impacto de la «quiebra del capitalismo global». Por último, la generación que está naciendo hoy en día tan sólo tendrá unos 20 años en 2030 (después que tras el «pico del petróleo» se alcance el del carbón) y estará empezando a enfrentarse a su vida adulta en un contexto de crisis muy profunda, pues habrá estallado ya el actual capitalismo global y estará iniciando el «largo declive de la civilización industrial», además de haber pasado toda su juventud en un contexto de fuertes crisis (Fernández Durán, 2011: 88-89). 
Otros autores comparten esta perspectiva. Este es el caso de Richard Heinberg, en cuya opinión, factores externos a la economía financiera hacen que la recuperación del crecimiento económico convencional sea prácticamente imposible. Existen tres factores básicos que se oponen firmemente al escenario de «recuperación del crecimiento»: el enrarecimiento de recursos naturales importantes, incluyendo las energías fósiles y algunos minerales; la proliferación de impactos ambientales derivados tanto de la extracción como del uso de recursos (incluyendo la combustión de combustibles fósiles), que conducen a costes crecientes motivados por los propios impactos y por los esfuerzos por evitarlos y paliarlos, y los cortocircuitos derivados de la incapacidad del sistema monetario y financiero para ajustarse a la escasez de recursos y a los crecientes costes ambientales (Heinberg, 2011).

Esta reflexión se sitúa en un telón de fondo de debates de mayor escala temporal. De acuerdo con el profesor de la Universidad Estatal de Utah, Joseph Tainter, las sociedades complejas han sido incapaces de forma recurrente de abordar su crisis de civilización a lo largo de la historia, y entraron en procesos de crisis profunda o colapso por distintas razones. Es lo que Tainter denomina «colapso de las sociedades complejas»: en determinadas condiciones históricas, las organizaciones sociopolíticas complejas encuentran crecientes problemas simplemente para conservar su statu quo. En estas circunstancias, mayores inversiones en mantener la complejidad alcanzada derivan en costes de distinta índole crecientes e inmanejables, de acuerdo con la ley de rendimientos decrecientes aplicada a las estructuras institucionales. Además, las sociedades complejas son grandes consumidoras de energía y recursos. Y cuando la utilidad marginal de cualquier nueva inversión en complejidad se convierte en negativa, el colapso y el paso a una situación de menos complejidad sociopolítica y desintegración estructural se convierte en una alternativa obligada En este sentido, el siglo xx podría haber sido el de la expansión, integración y complejización global, lo cual habría destruido en gran medida la diversidad local, todo ello gracias principalmente a la energía fósil. Por el contrario, el siglo Xxi podría ser el de la contracción y simplificación global, que no local, que podría reverdecer, al ritmo del enrarecimiento progresivo de la energía fósil (Tainter, 1988).

En ocasiones, las élites de estas civilizaciones abordaron salidas contraproducentes a estas crisis civilizatorias y precipitaron su colapso más rápido (Tainter, 1988). En esta ocasión, podría no estar siendo diferente: podríamos estar asistiendo a la incapacidad de las estructuras de poder de prever y reaccionar ante la crisis de la sociedad industrial. El intento de mantener las políticas propias de la fase de crecimiento (potenciación de la gran escala, urbanización, velocidad, especialización y competición) más allá del clímax de la civilización industrial, pese a que tales políticas se han adaptado bien a la fase ascendente, podrá producir un deterioro aún mayor de las condiciones de vida, institucionales y ambientales. Estas reacciones erróneas impedirían un hipotético descenso o una transición ordenada que sería sustituida por un colapso más brusco (Fernández Durán, 2011: 71-73). 
En cualquier caso, de cumplirse las perspectivas de estos «visionarios», la crisis de la civilización industrial no sería un proceso súbito y uniforme, sino un proceso largo, complejo y diferencial, con posibles altibajos, pero siempre en una cuesta debajo de creciente decadencia. Esto es lo que John Michael Greer $(2008,2009)$ ha llamado el «largo declive de la civilización industrial». Con apagones crecientes y generalizados a partir de 2030, crisis de los sistemas de transportes y del funcionamiento de las metrópolis, crisis del sistema cienciatecnología, organización social y cultural, estructuras institucionales, sistemas de valores, ética social, formas de cosmovisión, etc. El colapso progresivo de la civilización industrial sería un proceso lento, con altibajos, desigual espacialmente, pero también con importantes rupturas (Greer, 2008).

Pero, a pesar de todos estos plausibles augurios, en el corazón y en la mente de la sociedad industrial está arraigado el firme convencimiento de que esta civilización no sucumbirá como otras en la historia, y mucho menos el capitalismo global y sobre todo la sociedad de la imagen, la información y la comunicación, su última y deslumbrante conquista. "Las palabras declive o retroceso han estado desterradas durante más de 300 años, primero en Occidente, y luego en el mundo entero, al haber alcanzado las dinámicas modernizadoras los lugares más recónditos del planeta» (Fernández Durán, 2011: 78).

La fe en el progreso sin límites es hoy más fuerte en los nuevos centros emergentes (China, Brasil, Turquía, etc.) y en gran parte del Sur global que en Occidente, que está asistiendo al principio de su ocaso. Pero esa fe en el progreso se mantiene principalmente sobre la base de la realidad construida mediáticamente (medios de comunicación), que todavía es capaz de ocultar lo que acontece en la realidad real. Sin embargo, es razonable pensar que, en estas próximas dos décadas, irá quedando claro que es imposible generalizar el modo de vida occidental a todo el planeta, que esa idea ha sido un espejismo que ha durado apenas unas decenas de años. "Un espejismo sustentado en el saqueo de Gaia y en la explotación global, gracias a una sociedad hipertecnologizada que también va a empezar a tocar a su fin» (Fernández. Durán, 2011: 81).

\section{Críticas de las «ecologías del miedo" y énfasis en la acción política}

En síntesis, son numerosas las voces que advierten sobre el hecho de que la Tierra y muchos de los espacios que la componen están sumidos en un conflicto ecológico que puede cortocircuitar la sociedad humana en un futuro no muy lejano, de no adoptarse acciones urgentes e inmediatas para retrotraer la naturaleza a un estado de equilibrio más benigno. Son conocidas también las críticas a estos planteamientos desde posiciones definidas por mitologías productivistas y «tecno-utópicas». La más renombrada en la última década ha sido la obra de Bjorn Lomborg, El Ecologista Escéptico, animada, según señala el propio autor, por una entrevista con el economista americano Julian Simon, con una de cuyas frases se abre el libro: «Este es, brevemente, mi pronóstico a largo plazo: las condiciones materiales de la vida seguirán siendo mejores para la mayoría de las personas, en la mayoría de los países, la mayor parte 
del tiempo, indefinidamente. Dentro de uno o dos siglos, todos los países y la mayor parte de la humanidad estarán al mismo nivel o por encima de los actuales estándares de vida occidentales. No obstante, también creo que mucha gente seguirá pensando y afirmando que las condiciones de vida van cada vez peor» (citado por Lomborg, 2003: 9). Es el mismo mensaje que trasmite Paul Roberts cuando, en su documentado estudio titulado El fin del petróleo, dice: «En realidad, durante las próximas décadas, es muy probable que presenciemos toda clase de avances tecnológicos que no tengan nada que ver con los hidrocarburos, ni tampoco con la energía solar o eólica; avances que la mayoría de nosotros, criados en la era del petróleo, posiblemente no podemos ni llegar a imaginar, adelantos muy importantes que vendrán de ámbitos totalmente inesperados» (Roberts, 2010 (2004): 308). Pero en estas páginas no nos centraremos en esta línea de crítica a los anuncios de catástrofe, sino en la procedente de la teoría social crítica.

Desde esta perspectiva, Erik Swyngedouw denuncia que «los problemas ambientales se escenifican generalmente como amenazas universales a la supervivencia de la especie humana, anunciando el final prematuro de la civilización tal como la hemos conocido, en la línea de lo que Mike Davis denomina "ecologías del miedo"». El miedo, de acuerdo con esta perspectiva, es el nodo crucial a través del cual se construye la mayor parte de la narrativa ambiental de nuestro tiempo: «un miedo articulado en torno a la promesa de la desintegración socio-ecológica en algún tiempo futuro, alimentado por furiosos debates sobre la fecha exacta de su llegada» (Swyngedouw, 2011: 50).

Los efectos de estos planteamientos catastrofistas, que se construyen sobre la base de una visión de la naturaleza fuente de bienes, son perversos. Según este autor: la fantasía de imaginar una naturaleza benigna evita formular la pregunta políticamente sensible, pero vital, acerca de qué soluciones deseamos producir, cómo podemos alcanzarlas y qué clase de entornos deseamos habitar, reconociendo al mismo tiempo la contingencia radical e indecible de la naturaleza. Una política ambiental construida sobre una visión de una naturaleza singular, ontológicamente estable y armoniosa es necesariamente una política que erradica «lo político» del debate en torno a qué hacer con las naturalezas realmente existentes. La visión benigna de la naturaleza amenazada por desastres apocalípticos, subraya el autor, facilita un planteamiento postpolítico recorrido por el miedo y guiado por una preocupación de gestionar las cosas de modo que podamos preservar lo que poseemos en la actualidad (ibídem: 52-53).

De acuerdo con esta constatación, Erik Swyngedouw, siguiendo a Alain Badiou y a Slavoj Zizek, insiste en que «la ecología se ha convertido en el nuevo opio para las masas, reemplazando a la religión como eje alrededor del cual se articula nuestro miedo a la desintegración social y ecológica, pero también a partir del cual puede llegar la redención, si se presta suficiente atención a las premonitorias advertencias» (ibídem: 51). Por el contrario, la pregunta política clave debería ser «qué tipos de naturalezas deseamos preservar, construir o, si es necesario, borrar de la superficie del planeta (como, por ejemplo, el VIH) y cómo llegar a esa nueva situación» (ibídem: 60). 
Detrás de estos planteamientos, hay una profunda reflexión sobre la naturaleza, con evidentes implicaciones para la política ambiental. En este debate, Ulrich Beck - autor cuyo pensamiento complejo impide una caracterización simplista, como antes se advertía - sigue siendo un punto de referencia indiscutible: «Mi tesis es que ahora tenemos una "política de la Tierra" que no teníamos hace algunos años y que puede entenderse y organizarse en función de la dinámica y las contradicciones de una sociedad del riesgo global. ¿Qué es medio ambiente? ¿Qué es naturaleza? ¿Qué es "tierra virgen”? ¿Qué es "humano" en los seres humanos? Estas preguntas y otras parecidas tienen que ser recordadas, replanteadas, reconsideradas y rediscutidas en un contexto transnacional, aunque nadie tenga las respuestas» (Beck, 2002 (1999): 13).

Para el análisis sociológico de los problemas ecológicos, Beck propone un marco conceptual que permita captarlos no como problemas del medio ambiente o del mundo que nos rodea, sino del mundo interior de la sociedad: "En lugar de los conceptos clave, aparentemente evidentes de "naturaleza", "ecología” y "medio ambiente", basados en una oposición a lo social, el marco propuesto arranca más allá del dualismo de sociedad y naturaleza" (ibídem: 29-30). Puesto que, hoy más que nunca, la propia naturaleza no es naturaleza: es un concepto, una norma, un recuerdo, una utopía, un plan alternativo. La naturaleza es redescubierta, mimada, en un momento en el que ya no existe. En el debate ecologista, los intentos de utilizar la naturaleza como bandera contra su propia destrucción se basan en una falacia naturalista. Pues la naturaleza invocada ya no existe (ibídem: 32-33).

Pero si la naturaleza «en sí» no puede constituir la referencia analítica para la crisis ecológica y para una crítica del sistema industrial ¿qué puede desempeñar ese papel? La respuesta más frecuente es: la ciencia de la naturale$z a$, de acuerdo con la cual y por medio de determinadas fórmulas técnicas —indicadores de presiones, impactos, estado del aire, del agua, o de los suelos, modelos climatológicos o bucles de realimentación de modelos de simulación en todo tipo de ecosistemas-, se puede calibrar, comprobar si el daño a los ecosistemas es tolerable o no lo es. Este enfoque, sin embargo, tiene al menos tres inconvenientes. En primer lugar, conduce directamente a la «ecocracia», que difiere de la tecnocracia en la mayor extensión de su poder (gestión global) coronada por la buena conciencia que la caracteriza (Beck, 2002: 33-34). En esta primera crítica coincide Swyngedouw, que denuncia la aristocracia de las ciencias naturales supuestamente neutral que en sus dictámenes mezcla, o incluso intercambia, "hechos» y "valores», traduciéndolos sin la oportuna mediación política pública. De esta manera, estos especialistas se inmiscuyen directamente en el dominio de la política y, como gerentes expertos, se convierten en parte integral de las instituciones y los foros de gestación de políticas (Swyngedouw, 2011: 53).

En segundo lugar, desde esta perspectiva crítica, se considera que la ciencia de la naturaleza ignora la importancia de las percepciones culturales y del conflicto o diálogo intercultural, que explican que los mismos peligros se presenten según estos contextos de manera muy diferente. Es más, los enfoques de las 
cuestiones ecológicas por parte de la ciencia natural implican modelos culturales de la naturaleza ocultos. La consecuencia es que ningún tipo de expertos podrá responder jamás a la pregunta política clave: ¿Cómo queremos vivir? Lo que la gente está o no está dispuesta a aceptar no se deriva de ningún diagnóstico técnico o ecológico de los peligros, sino que, antes bien, debe convertirse en objeto de diálogo global entre culturas (Beck, 2002: 33-34).

Pero por contradictorios que puedan ser los enfoques esencialista-realista y constructivista en sus métodos y sus supuestos básicos, ambos coinciden en el diagnóstico de la situación actual, caracterizada como la sociedad del riesgo global. El realismo, es cierto, enfatiza la sociedad del riesgo global y el constructivismo, la sociedad del riesgo global. Podríamos decir, aclara Beck, que el realismo concibe la problemática ecológica como "cerrada», en tanto que el constructivismo mantiene su apertura en principio. Para uno, son los peligros (los escenarios del desastre total) de la sociedad del riesgo global los que constituyen el centro principal de atención; para el otro, las oportunidades, los contextos en los que actúan los actores, son lo prioritario (Beck, 2002: 39-40).

Con matices y énfasis diferentes, el conjunto de la teoría social crítica se sitúa en esta perspectiva. Para Bruno Latour, no existe algo así como la naturaleza en sí y para sí misma, ni algo como la sociedad (o la cultura). La dificultad del análisis de fenómenos ambientales como la sequía procede de su carácter simultáneamente multidimensional, «a la vez real, como la naturaleza, narrado como el discurso, y colectivo, como la sociedad» (Latour, 1993: 6). El conjunto de realidades (humanas y no humanas) que pueblan el mundo está formado por híbridos de naturaleza y cultura que se multiplican incesantemente. Realidades como, por ejemplo, los gases de efecto invernadero, la oveja clonada Dolly, una presa hidráulica, una botella de leche, redes de abastecimiento de agua o un sistema de aire acondicionado en un centro comercial son, simultáneamente, realidades socioculturales y físico-naturales y «su coherencia, es decir, su relativa sostenibilidad espacial y temporal, es predicada a partir de redes ensambladas de relaciones humanas y no humanas» (Swyngedouw, 1999: 4 y 2011: 44).

Richard Levins y Richard Lewontin, por su parte, detestan las visiones simplistas, reduccionistas y teleológicas de la naturaleza y, en última instancia, homogeneizadoras. No existe una naturaleza singular, no hay ningún estado natural transcendental de las cosas de carácter transhistórico y/o transgeográfico, sino, por el contrario, un abanico de diferentes naturalezas históricas, relaciones y medios ambientes sujetos a cambios y transformaciones continuos, ocasionalmente dramáticos o catastróficos, y raramente previsibles en toda su extensión. Para estos autores, no puede realizarse ninguna afirmación universal o fundamental acerca de lo que es la naturaleza, lo que debería ser o hacia donde debería dirigirse. Tampoco para Stephen Gould existe seguridad alguna en la naturaleza, que es imprevisible, errática, se mueve de forma ciega y espasmódica. "Por decirlo sin rodeos, reducir (o no hacerlo, como es el caso) las emisiones de $\mathrm{CO}_{2}$ afecta al clima global y conforma patrones socioecológicos de diferentes modos (que, por supuesto, merecen tanto una exploración 
científica como una preocupación ética), pero tal proceso, aunque tuviera éxito, no produciría en sí mismo una sociedad "buena" en un ambiente "bueno"" (Swyngedouw, 2011: 46). Las naturalezas realmente existentes son siempre complejas y caóticas, a menudo imprevisibles, radicalmente contingentes, histórica y geográficamente variables, arriesgadas y configuradas de modos infinitamente enmarañados. «En otras palabras, no hay ninguna naturaleza ahí fuera que precise o requiera la salvación en nombre de la propia naturaleza o de una humanidad genérica. No hay nada fundacional en la naturaleza que requiera, exija o precise ser sostenido" (Swyngedouw, 2011: 49).

La llamada a abandonar la naturaleza no pretende, sin embargo, sugerir que debamos ignorar, ni mucho menos olvidar, lo real de las naturalezas o, más precisamente, las relaciones socioecológicas de carácter diverso, múltiple, caprichoso, contingente y a menudo impredecible de las que formamos parte (Swyngedouw, 2011: 61). Aunque la naturaleza no existe más allá de las cadenas metonímicas que le proporcionan un cierto sentido, hay, por supuesto, todo un abanico de entornos, de acoplamientos de relaciones socionaturales. Los entornos son el resultado histórico-específico de procesos sociofísicos. Todos los procesos socioespaciales, de hecho, son construidos invariablemente en base a la circulación, el metabolismo y la codificación de procesos sociales, culturales, físicos, químicos o biológicos, pero su resultado es contingente, a menudo imprevisible, enormemente variado, arriesgado. Los procesos de cambio metabólico nunca son social o ecológicamente neutros. La producción de ordenaciones socioambientales conlleva conflictos fundamentalmente políticos y ha de ser dirigida en términos políticos. La cuestión es desvelar quién gana y quién paga, quién se beneficia y quién sufre - y de qué modo- los procesos particulares del cambio de circulación metabólica (Swyngedouw, 2011: 62).

\section{La distribución espacialmente desigual de los impactos del metabolismo social}

El incremento de la desigualdad — desigualdad social y desigualdad espacial— se va constituyendo de manera insistente en uno de los aspectos centrales del debate. «Nunca el mundo había sido tan desigual y nunca los niveles de concentración de la riqueza habían alcanzado proporciones tan obscenas" (Nogué y Romero, 2006: 20). O, como dice Ricardo Méndez, «dos décadas de globalización han reforzado las desigualdades preexistentes, concentrando la riqueza y el poder en unos pocos territorios, empresas y grupos sociales, frente a la exclusión o la escasa participación en los beneficios de otros muchos» (Méndez, 2008: 256).

La concentración de riqueza y poder condicionan los procesos que se refieren a la base material del sistema de producción. Como dice Michael Zürn, entre la destrucción medioambiental como resultado del bienestar y la destrucción medioambiental como resultado de la pobreza existe una diferencia esencial. Mientras que las amenazas ecológicas causadas por la riqueza se derivan de la externalización de los costes de producción, en el caso de la destrucción 
ecológica motivada por la pobreza son los pobres quienes se destruyen a sí mismos, con efectos colaterales para los ricos: «la destrucción medioambiental causada por la riqueza se distribuye igualitariamente en todo el mundo, mientras que la destrucción medioambiental causada por la pobreza golpea en lugares concretos y sólo se internacionaliza en forma de efectos colaterales que se manifiestan a medio plazo» (Michel Zürn, 1995, cit. en Beck, 2002 (1999): 54-55).

Hace tiempo que se viene cuestionando la hipótesis de la llamada curva medio ambiental de Kuznets, que explora la relación existente entre crecimiento económico y calidad ambiental ${ }^{1}$. Simon Kuznets intentaba demostrar que, si bien en el corto plazo el crecimiento económico genera deterioro ambiental, en el largo plazo la calidad del medio ambiente mejora con el incremento en los ingresos. Trabajos como los de Carpintero (2005) muestran que la «desmaterialización» de la economía no está teniendo lugar: aunque la tendencia a desplazar fuera de las fronteras de los países más desarrollados las primeras fases de extracción y tratamiento de los recursos unida a la mejora de la eficiencia observada en los procesos parciales que albergan, pueda disminuir su input directo de materiales (DMI), la realidad es que la mayoría de ellos sigue aumentando el requerimiento total de materiales (TMR) per cápita ${ }^{2}$. Con ese desplazamiento, se puede mejorar el medio ambiente local de los países ricos, pero a costa de un mayor deterioro del medio ambiente global, utilizado como fuente de recursos y sumidero de residuos (Naredo y Valero, 1999: 22). Las «externalidades» negativas del desarrollo se trasladan desde los propios territorios hacia el resto del planeta. Este fenómeno está directamente vinculado a la «profunda asimetría existente entre valoración monetaria y coste físico a lo largo del proceso económico en general, que da pie a la desigualdad de costes físicos que subyace bajo la igualdad monetaria de los intercambios en el propio comercio mundial» (ibídem: 41$)^{3}$.

Más allá de este debate fundamental, una característica básica de la economía mundial es el reparto muy desigual del uso de los materiales y la energía, cuyo transporte ha aumentado a lo largo del tiempo. Durante las primeras

1. Kuznets formuló su famosa curva en los años cincuenta para relacionar la distribución de la renta con el nivel de renta y solo más recientemente otros autores utilizaron su curva para relacionar el deterioro ambiental con el nivel de renta. Por lo tanto, no es riguroso atribuir al propio Kuznets haber diseñado su curva con el afán moderno de relacionar renta y medio ambiente (comunicación personal de José Manuel Naredo; ver también Naredo, 2010: 42-43, nota 14).

2. El input directo de materiales (IDM) o requerimiento directo de materiales (RDM) se refiere a los materiales con valor económico empleados en las actividades de producción y consumo. Los flujos materiales ocultos son los materiales extraídos y movilizados, que no son aptos para ser introducidos en las actividades de producción y consumo y que nunca forman parte de la valoración económica. El requerimiento total de materiales (RTM) es la suma de los flujos materiales directos y de los flujos materiales ocultos, tanto domésticos como importados.

3. Sobre el reduccionismo imperante en la atribución de valores por parte de la economía convencional, que impone una creciente asimetría entre el valor monetario y el coste físico y humano de los procesos, ver nota 4 . 
etapas del desarrollo industrial, la explotación de los principales minerales utilizados se realizaba básicamente en los países industrializados: los principales productores de hierro y carbón eran los principales países consumidores de los mismos. Incluso en recursos con yacimientos tan mal distribuidos en el mundo como la bauxita y el petróleo, la importación no llegaba a la cuarta parte de las necesidades de los países ricos. Sin embargo, a partir de mediados del siglo Xx, el consumo de carbón y de petróleo en estos países se multiplicó por más de cinco y de diez, respectivamente, lo cual dio lugar a un incremento del desajuste entre los requerimientos y las disponibilidades de sus territorios. Lo mismo ocurrió con la mayoría de los minerales, para los que estos países son generalmente importadores netos. A los tradicionales centros receptores, es decir, Europa, Estados Unidos y Japón — la «Triada del poder», como la definió Kenichi Ohmae (Méndez, 2008: 225)—, el transporte de petróleo añade los «dragones» del sureste asiático. Su emergencia económica ha significado la implantación de industrias exigentes en energía y contaminación, que los ha convertido en la tercera zona receptora neta de petróleo a escala planetaria (Naredo y Valero, 1999; Naredo, 2010: 57-59).

Pese a las mayores tasas de crecimiento registradas en la etapa más reciente en el este, en el sureste de Asia y en algunos países de Latinoamérica, los países de la Tríada aún concentraron en 2001 el 64,8\% del valor, medido en dólares, de las exportaciones y el $68,4 \%$ del de las importaciones de mercancías, y llegó al 71,4\% y al 68\% en el caso de los servicios. Hay que destacar el rápido crecimiento en el peso relativo de los países del sureste asiático, que, junto a China, superaban en 2001 la exportación de mercancías de Estados Unidos: el $13,9 \%$ y el $12,2 \%$, respectivamente, cuando esas cifras eran del $3,9 \%$ y del 17,0\% en 1963 (Méndez, 2008: 228).

Pero, para entender la realidad de los intercambios que genera la economía mundial, es necesario complementar los datos expresados en agregados monetarios con datos expresados en magnitudes físicas. En este sentido, la cuarta parte de los 6.092 millones de toneladas movilizados por el comercio internacional en el año 2000 se quedó en los países ricos (mayoritariamente, combustibles fósiles, otros derivados de actividades extractivas y, en mucha menor medida, productos agroforestales y pesqueros). Este conjunto de países sólo es exportador neto de productos manufacturados, por un tonelaje muy inferior al de los productos primarios importados. El requerimiento directo de materiales (RDM) medio per cápita en el mundo era, en ese año, de 7 toneladas per cápita, mientras que ascendía a 17 en Japón, a 20 en USA, a 22 en Alemania y a 38 en Holanda. A la vez que el requerimiento total de materiales (RTM) pasa de $18 \mathrm{Tm}$ per cápita para la media mundial a 46, 84, 86 y 84, respectivamente, en estos países. Esta enorme entrada neta de recursos acaba convirtiéndose en residuos que sólo en escasa medida son objeto de recuperación o reciclaje, lo cual provoca que la acumulación de residuos sea el primer problema de "política ambiental» en estos países. Paradójicamente, el debate no se orienta prioritariamente a la causa (el manejo masivo de recursos traídos de todo el mundo y los impactos causados en los países de origen), sino a sus 
efectos (los residuos y el deterioro que ocasionan en los países receptores) (Naredo, 2010: 59-63).

Esta es la dinámica que da lugar al actual concepto de deuda ecológica, que según el Acuerdo de los Pueblos, aprobado en Cochabamba (Bolivia) en abril de 2010, se refiere a la responsabilidad contraída por los países industrializados del Norte, sus instituciones, la élite económica y sus corporaciones por la apropiación gradual y el control de los recursos naturales, así como por la destrucción del planeta causada por sus patrones de consumo y producción. «Basándose en esta definición, los pueblos en el Sur se sienten acreedores de esta deuda, que tiene como base al actual modelo de producción industrial, la producción de residuos, la emisión de gases de efecto invernadero, el capitalismo y el libre mercado" ${ }^{4}$. Aunque todavía afectada por una débil operatividad y escasas posibilidades de reconocimiento legal, el concepto de deuda ecológica - que engloba problemáticas tales como los intercambios comerciales económica y ecológicamente desiguales, la generación de pasivos ambientales, la biopiratería y el cambio climático - es de utilidad como herramienta interdisciplinaria para denunciar la insostenibilidad ecológica y social del sistema económico mundial actual, así como para cuestionar la legitimidad de la deuda externa (Villalba, 2008).

Un aspecto especialmente problemático de este fenómeno general es la gestión de los desechos peligrosos que ha estado presente en la agenda ambiental internacional a partir de comienzos del decenio de 1980, lo cual dio lugar al Convenio de Basilea sobre el control de los movimientos transfronterizos de desechos peligrosos y su eliminación, aprobado en 1989 en respuesta a una clamorosa protesta tras el descubrimiento en África y otras partes del Sur global de depósitos de desechos tóxicos importados de los países centrales. A lo largo de este periodo, las situaciones de conflicto más significativas que se han detectado son: realización de exportaciones sin seguir el procedimiento del convenio; reclamaciones de países de tránsito y de importación por no haber sido notificados o no haber dado su consentimiento; dificultad de controlar las salidas y los ingresos de residuos; falta de definiciones claras (qué es un residuo, qué es un país de tránsito, cómo deben ser los seguros). Desde la firma del tratado, la polémica sobre la libre exportación de residuos ha vuelto a aflorar en diversas ocasiones, incluidas las cumbres de Río (1992) y Johannesburgo (2002), lo cual ha originado peticiones de cese de este tipo de actividades (PNUMA, 2011). Pese a estos avances, la creciente presión de los países ricos para desembarazarse de los residuos que generan por vías baratas y efectivas ha llevado a considerar la posibilidad de depositarlos en las grandes profundidades de los mares, que pueden constituir el basurero ideal de acuerdo con la lógica dominante de no exigir a los agentes económicos que se responsabilicen de reciclar, o al menos de neutralizar, in situ los residuos que originan.

4. Acuerdo de los Pueblos, Conferencia Mundial de los Pueblos sobre el Cambio Climático y los Derechos de la Madre Tierra, 22 de abril de 2010, Cochabamba, Bolivia (http://www. deudaecologica.org/Que-es-Deuda-Ecologica/). 
En síntesis, existen profundas diferencias entre el modelo de dominación colonial de hace un siglo y el actual. En el modelo anterior, los estados metropolitanos ejercían su dominio instalando administraciones coloniales en otros territorios, para extraer de ellos ciertos productos primarios, venderles otros elaborados y obtener ganancias mediante el comercio colonial que eran reinvertidas, en parte y sobre todo, en forma de infraestructuras (puertos, ferrocarriles, etc.) tendentes a ampliar dicho comercio. A la vez, se producía normalmente un flujo de población desde las metrópolis hacia los territorios a colonizar. En aquel modelo, los residuos y los deterioros apenas trascendían del nivel local en el que se generaban. Actualmente, hay países ricos cuya situación privilegiada se sigue apoyando básicamente en el intercambio comercial. Sin embargo, en otros países con sistemas financieros más capaces, este modelo ha ido evolucionando hacia otro en el que se impone la hegemonía financiera sobre la comercial, apoyada en un potente aparato militar que sigue siendo el factor clave 5 .

En este modelo de globalización, se amplía considerablemente la capacidad de compra sobre el mundo por parte de los ricos y, por ende, el flujo neto de energía y materiales que reciben desde el resto del mundo, que les ayuda a cuidar la calidad de su medio ambiente local. Pero la globalización de la extracción y el comercio de recursos traen consigo la expansión también global de los residuos, que, a diferencia del modelo anterior, transciende la escala local. Se produce así una globalización de las extracciones y los impactos destructivos y contaminantes de la especie humana sobre el planeta (con el cambio climático como su expresión máxima), que corre pareja a las globalizaciones económica económico-financiera y militar que la apuntalan y promueven (Naredo, 2010: 106-110).

\section{El debate sobre el decrecimiento}

En este contexto socionatural y discursivo, en los últimos años, primero en Francia e Italia, luego, con otras terminologías, en el mundo anglosajón (Movimiento sobre Transiciones Económicas Globales) y en el Sur global, el término decrecimiento (décroissance, degrowth, decrescita) está actuando de provocación en el debate. Está sirviendo para llamar la atención sobre las consecuencias de la lógica del crecimiento económico ignorando la naturaleza de las producciones en las que se basa el propio crecimiento y el absurdo de mantener la evolución de los indicadores estrictamente monetarios como criterio de valoración de los procesos económicos.

Un punto de referencia clave es que, después de 20 años de experiencia, no se puede seguir confiando en la estrategia de la eficiencia y la desmaterialización

5. EEUU mantiene una red global de más de 750 bases militares. Esta inmensa máquina militar requiere un enorme sistema de suministro que comienza en la industria de armamentos que, a su vez, depende de un prodigioso torrente de fondos públicos permanentemente en expansión. En la actualidad, los EEUU están implicados en «operaciones especiales» en 120 países y usan unidades de comandos de élite en asesinatos, redadas contraterroristas, formación de tropas extranjeras y operaciones de inteligencia (Heinberg, 2012, 1-2). 
de la economía (es decir, el desacoplamiento del uso de materiales y energía del crecimiento). La persistencia del llamado «efecto rebote" («efecto Jevons») se ha hecho indiscutible: constantemente se confirma que, en el marco de una economía en expansión, los ahorros producidos por la eficiencia se reasignan sistemáticamente a nuevos consumos de recursos físicos. El caso del agua es paradigmático: los enormes avances en eficiencia (descensos de entre un 15\% y un 25\% de dotaciones en la mayoría de las ciudades españolas entre 1991 y 2011) no han reducido la presión sobre los ecosistemas acuáticos. Insistentemente se pone de manifiesto que, además de eficiencia, la limitación y la reducción de la escala de la producción física son condiciones necesarias para avanzar hacia la reducción del metabolismo de materiales y energía (Schneider et al., 2010: 512 y 517).

Los teóricos del decrecimiento distinguen entre depresión (un decrecimiento no planificado, con deterioro de las condiciones sociales, en el marco de un régimen de crecimiento) y decrecimiento sostenible (una transición voluntaria, suave y equitativa hacia un régimen de menor producción y consumo). Las propuestas de Serge Latouche (Le pari de la décroissance, 2006), difundidas y debatidas en España por Francisco Fernández Buey, Joaquim Sempere, Carlos Taibo, Joan Martínez-Alier y otros, plantean la necesidad de construir formas de vida basadas en las relaciones sociales, la cercanía, la austeridad, la vida en común y la ralentización del tiempo. Estas dimensiones, defienden estos autores, lejos de ser limitantes, son las que enriquecen la vida, como pondrían de manifiesto estudios sobre la felicidad subjetiva, como los de Clive Hamilton, que concluyen que, a partir de determinado nivel de ingresos, el incremento en estos últimos - resultado, generalmente, de un aumento paralelo en carga de trabajo- apenas proporciona ganancias en materia de felicidad objetiva. Los trabajos de Hamilton son aportaciones recientes que vienen a continuar la investigación sobre la "paradoja de Easterlin», que, ya en 1974, había puesto de manifiesto (aunque el debate sobre la metodología utilizada aún no ha terminado) la falta de correlación entre felicidad y PIB, una vez alcanzados ciertos niveles de satisfacción de las necesidades básicas.

Sin duda nos encontramos frente a planteamientos (con profundas raíces en la historia del pensamiento) que apuntan a la piedra angular del debate sobre la sostenibilidad: la necesidad de realizar un cambio cultural profundo, un cambio de valores, objetivos y «sensibilidades», en la línea de lo que viene propugnando Edgar Morin, para quien "cuando un sistema es incapaz de resolver sus problemas vitales por sí mismo, se degrada, se desintegra, a no ser que esté en condiciones de originar un metasistema capaz de hacerlo y, entonces, se metamorfosea [...]. Aunque parece posible corregir ciertos males, es imposible frenar la oleada técnico-científico-económico-civilizatoria que conduce al planeta al desastre. Y, sin embargo, la historia humana ha cambiado de vía a menudo. Todo comienza siempre con una innovación, un nuevo mensaje rupturista, marginal, modesto, a menudo invisible para sus contemporáneos [...] Hay que promover, de manera desmundializadora, la alimentación de proximidad, los artesanos de proximidad, los comercios de proximidad, las 
huertas periurbanas, las comunidades locales y regionales [...]» (Morin, 2010 y 2011:31).

Merece la pena subrayar la referencia a la tecnociencia, puesto que la crítica a ésta es un aspecto central del nuevo ideario: la investigación y las innovaciones tecnológicas, en ese proceso de metamorfosis que propugna Morin, deberían implicar aportaciones para reducir el consumo en lugar de alimentar una espiral de innovaciones orientadas al incremento exponencial del mismo. Este tema tiene una gran importancia. Siendo el optimismo tecnológico la clave de las argumentaciones productivistas y neoliberales en el debate sobre el futuro de la "crisis ambiental», las críticas al propio sistema tecnocientífico, como factor del propio problema, son fundamentales. Es significativa la posición del moderado Jared Diamond, que señala: «Todos nuestros problemas actuales son consecuencias negativas y no deseadas de la tecnología de que disponemos. Los rápidos avances de la tecnología a lo largo del siglo xx han originado nuevos y arduos problemas a un ritmo mucho mayor que aquel al que han solucionado los viejos. Esa es la razón por la que estamos en la situación en la que nos encontramos» (Diamond, 2007: 653).

En sintonía con estas ideas, la proposición paradigmática del decrecimiento es que el progreso humano sin crecimiento económico es posible. El decrecimiento sostenible implicaría una reducción del producto interior bruto (PIB) tal como hoy se mide, debido a la reducción de actividades de producción y consumo a gran escala y muy intensivas en recursos. El decrecimiento sostenible no significaría, sin embargo, un decrecimiento generalizado y por igual: algunas actividades económicas de pequeña-media escala (energías renovables, sistemas públicos de transporte, rehabilitación de viviendas) y grupos sociales y regiones empobrecidas necesitarían crecer selectivamente. Por el contrario, el crecimiento de una empresa, sector, país o región que externalice sus costes en otros territorios no sería aceptable. En este sentido, una línea de crítica hacia el movimiento decrecentista insiste en la obviedad de sus planteamientos y en el error de retomar un debate (la insuficiencia del PIB como indicador de bienestar social) ya claramente resuelto. Pero si bien la maduración de la crítica a los indicadores convencionales de desarrollo es un hecho (hoy ya no se sorprende a un auditorio de nivel cultural medio al explicarle que los incendios forestales o los accidentes de tráfico incrementan el PIB), la realidad es que la presencia del PIB en el debate político-social-mediático actual no sólo no se ha reducido, sino que también se ha acentuado: hoy el público espera con ansiedad la información sobre variaciones de décimas en el crecimiento (o decrecimiento) del PIB, lo que determinará la salida o la permanencia en la recesión.

En cualquier caso, los representantes del decrecimiento no se centran, en general, en la reducción del PIB en sí mismo como un objetivo, sino en la redefinición del bienestar social e individual, citando, por ejemplo, la idea de «la alegría de vivir» de Georgescu-Roegen, lo que nos vuelve a situar en las raíces profundas (milenarias) de la nueva corriente: el énfasis en los bienes relacionales, aquellos en los que la propia relación constituye el valor del bien (Schneider et al., 2010). Bienes que nacen de relaciones interpersonales, de 
encuentros en los que son esenciales la identidad y la voluntad de las partes implicadas.

En este sentido, son notables las conexiones entre la corriente del decrecimiento y el pensamiento feminista, aunque no todo son coincidencias (Moral Espín y Coronado, 2010). Ambas subrayan la centralidad de la idea de bienestar y calidad de vida, desvinculadas del consumo mercantil, los ingresos, el salario y el empleo. Cuestionan la validez de los indicadores económicos convencionales ("fuente principal de profundos engaños») por no incluir los costes ambientales ni el agotamiento de recursos, pero también por no contabilizar el trabajo doméstico y voluntario. Ambas cuestionan la centralidad de los mercados y subrayan los peligros que conlleva una mercantilización masiva de las actividades; ponen en cuestión la centralidad del empleo, reclaman la reducción de la jornada laboral y la posibilidad de desarrollar distintos trabajos y actividades a lo largo del ciclo vital según los deseos y las circunstancias personales; hablan de la necesidad de desarrollar "políticas de tiempo": tiempo para el desarrollo personal, tiempo para la participación, para "los cuidados», para el desarrollo de actividades artísticas o artesanales, de juego, contemplación o, simplemente, para la felicidad de la vida; ambos ponen énfasis en lo relacional y en la importancia de las emociones, en las relaciones humanas, en la «sostenibilidad de la vida» (Carrasco, 2001). O, como dice Ivan Illich, en la "convivialidad», puesto que la sociedad industrial ha promovido una nueva elite de profesionales, cuyo trabajo consiste en convencernos a todos de que «necesitamos lo que no necesitamos» y, frente a ella, se puede oponer, por decirlo con las propias palabras de Illich, los «instrumentos para la convivialidad» (tools for conviviality) (Illich, 1978).

\section{Críticas a las propuestas decrecentistas}

Esta corriente de pensamiento ha recibido duras críticas teóricas y políticas por parte de autores que, en algunos casos, están muy próximos a sus planteamientos. En este sentido, José Manuel Naredo señala que el deterioro ambiental y la polarización social también se producen en situación de estancamiento o de decrecimiento de los agregados monetarios recogidos en el PIB y otros indicadores. Consiguientemente, lo importante no sería cuestionar las tasas formales de crecimiento de esos agregados, sino las reglas de valoración subyacentes. «Habría que corregir las reglas del juego económico (enderezar la Regla del Notario ${ }^{6}$ y establecer marcos institucionales que propicien la igualdad,

6. El concepto de Regla del Notario se refiere al reduccionismo imperante en la atribución de valores por parte de la economía convencional, que impone una creciente asimetría entre el valor monetario y el coste físico y humano de los procesos. Es decir, a mayor coste físico y trabajo penoso, menor valoración monetaria. Esta asimetría creciente traslada subrepticiamente a las actuales sociedades mercantiles y democráticas los valores propios de sociedades jerárquicas anteriores. Este mecanismo ha sido identificado, con la denominación de Regla del Notario, por José Manuel Naredo, quien lo ha formalizado matemáticamente, cuantificado y ajustado para ilustrar su aplicación a procesos reales (Naredo y Valero, 1999; Naredo, 2010). 
la solidaridad, la cooperación, etc.) para cambiar su orientación y reconvertir los procesos hacia horizontes ecológica y socialmente más saludables que los actuales» (Naredo, 2011:32-33). Recuerda Naredo que, ya en 1987, él mismo señalaba que el estancamiento o el decrecimiento de los agregados monetarios suele moderar, pero no evitar, el deterioro del medio natural que ocasiona el proceso económico. Cualquier tasa de crecimiento de los agregados monetarios puede ser compatible con la aplicación de muy diversas tecnologías e impactos sobre el entorno y sobre la vida de las personas, por lo que no cabe hablar de crecimiento cero o de decrecimiento como solución a la crisis ecológica, sin precisar su conexión con el mundo físico, biológico e incluso utilitario. «Sólo la reconversión del proceso puede evitarlo en la medida en la que - siguiendo el ejemplo de la biosfera- apoye sus flujos físicos en fuentes renovables y cierre los ciclos de materiales obtenidos de la corteza terrestre, reconvirtiendo los residuos en recursos o inertizándolos y reinsertándolos en el entorno sin deteriorarlos» (Naredo, 1987, 3a ed., 2003: 365).

Naredo niega que Nicholas Georgescu-Roegen pueda ser considerado un precursor del decrecimiento. Fue a Jacques Grinevald, dice Naredo, al que se le ocurrió poner la palabra "decrecimiento» en el título del libro Demain la décroissance, que traducía y divulgaba en francés algunos de los textos de Georgescu-Roegen, en cuyos títulos originales no figuraba esa palabra. Es más, ninguno de los textos originales de este autor, anteriores o posteriores a la aparición del libro introducido por Grinevald, incluye en el título la palabra «decrecimiento» o se dedica a defender el «decrecimiento» como propuesta. Es la reconversión, y no el decrecimiento, lo que propone Georgescu-Roegen, aunque considera irrealista la posibilidad de erradicar o invertir por completo el carácter entrópico del proceso económico y la naturaleza depredadora y consumista del ser humano (Naredo, 2011: 30).

Cuando Herman Daly se declaró partidario del crecimiento cero (el precedente del actual concepto de decrecimiento) tras la aparición del primer Informe del Club de Roma sobre Los límites del crecimiento (1971), GeorgescuRoegen criticó con vehemencia la propuesta del «estado estacionario» formulada por Daly (Naredo, 2011: 29). La propuesta del estado estacionario, dice Naredo, "pasó sin pena ni gloria a la historia, como una moda pasajera, como seguramente ocurrirá también con la propuesta del decrecimiento». Lo que no quita para que sigan decreciendo sordamente las dotaciones de recursos y se sigan esquilmando, de una u otra manera, los recursos y el ambiente planetarios, en una huida hacia adelante, que no cambiará mientras no cambien las reglas del juego económico habitual que impulsan este proceder. La reconversión del sistema que propugna Naredo entrañaría el aumento del recurso a ciertas energías renovables y la reducción del manejo de otras más limitadas y contaminantes, el mayor uso, reutilización y reciclaje de ciertos materiales y la reducción de la utilización de otros, «lo cual es incompatible con la propuesta del decrecimiento como objetivo generalizado" (Naredo, 2011: 30-31).

Realmente, conociendo los textos de los autores identificados con la propuesta de decrecimiento, no se puede evitar la sensación de que estas críticas 
son un tanto ociosas, en la medida en que, como se muestra en el apartado anterior, están asumidas por estos autores. El propio Herman Daly ya señalaba hace muchos años que uno de los argumentos «menos ingenioso» contra el estado estacionario de la economía (SSE, Steady State Economy) fue el presentado por los editores de Fortune en 1976, que señalaban que el país ya había atravesado un periodo real de crecimiento cero (1973-1975), un periodo recordado como la peor recesión desde los años treinta. Fortune, decía Daly, identificaba el SSE con la quiebra de la economía del crecimiento, pero una situación de no-crecimiento puede aparecer de dos maneras: como la quiebra de la economía del crecimiento o como el éxito de la economía de estado estacionario. Ambos casos son "tan diferentes como la noche y el día", dice Daly: nadie niega que la incapacidad de crecer por parte de la economía del crecimiento provoca desempleo y sufrimiento. Es precisamente para evitar el sufrimiento de la quiebra de la economía del crecimiento (porque sabemos que el crecimiento no puede continuar) por lo que se debe abogar por el SSE. Con una célebre y, en mi opinión, poco afortunada imagen, Daly señala que el que un avión caiga al suelo si trata de mantenerse estacionario en el aire refleja el hecho de que los aviones están diseñados para el movimiento continuo, pero que ese no es el caso de los helicópteros (Daly, 1989).

La debilidad de la imagen de Daly es que apunta a que el problema tiene una solución técnica (¿qué es lo que diferencia a un avión de un helicóptero?), en este caso, de costes materiales y energéticos por unidad de peso desplazada incluso mayores. Como dice Ted Trainer, algunos decrecentistas (y esto sería en cierta medida aplicable a Daly) no entienden bien las implicaciones políticas radicales de una economía de estado estacionario: actúan como si se pudiera o se debiera eliminar el elemento del crecimiento, mientras se deja el resto más o menos tal cual. Esta estrategia no es realista, porque la economía real no es una economía que «tiene crecimiento»; es una "economía de crecimiento», un sistema en el que la mayoría de las estructuras y de procesos centrales entrañan crecimiento. Si se eliminara el crecimiento, habría que encontrar modos radicalmente diferentes de llevar a cabo muchos procesos. Los decrecentistas actúan como si el crecimiento fuera la única cosa, la cosa primordial o suficiente que hay que resolver, sin embargo, los problemas de fondo no pueden resolverse a menos que se reconfiguren de manera radical determinados sistemas y estructuras fundamentales de la sociedad capitalista de consumo (Trainer, 2011). La reflexión de Trainer apunta al corazón del debate: la necesidad intrínseca de crecimiento y acumulación constante por parte del sistema capitalista, que obliga de una u otra forma a esta huida hacia delante.

\section{Dificultad de las alternativas}

Riechmann analiza las dificultades del proceso de transición empezando por señalar que los avances se producen en los factores que, aún siendo necesarios, no cuestionan las propias «reglas del juego» del sistema. Es el caso de los avances en eficiencia, que, como se ha constatado en anteriores procesos de 
«modernización ecológica», no impiden que, a consecuencia del denominado «efecto rebote», las presiones y los impactos sigan creciendo: los procesos son más eficientes pero el volumen de producción crece más que el porcentaje de reducción de recursos requeridos. También se ha avanzado en la idea de la «biomímesis» (imitar la naturaleza i aprender de ella), consistente en impulsar pautas de acción que minimicen las alteraciones de los ciclos funcionales naturales en la resolución de las necesidades (Prats, 2009: 13).

En cambio, los principios de precaución y de autolimitación, los que afectan a los mecanismos básicos, implican fundamentalmente cambios de estrategias sociales, culturales e institucionales. Son los que resultan más ajenos y se contraponen más a la dinámica de funcionamiento del sistema económico y es muy poco lo que se ha avanzado en ellos. Existen elementos socioculturales muy fuertes, como la cultura expansiva del ir más allá, la insistencia en lo ilimitado de los deseos humanos, en la mejora indefinida de la condición humana que se identifica con el consumo creciente de bienes y servicios (Riechmann, 2007). Como escribió Nicholas Georgescu-Roegen «[...] quien crea que puede diseñar un plan para la salvación ecológica de la especie humana no comprende la naturaleza de la evolución y ni siquiera la de la historia, que es la de una lucha permanente bajo formas siempre nuevas, no la de un proceso físico-químico predecible y controlable como los de cocer un huevo o enviar un cohete a la Luna» (citado por Riechmann, 2007, y Naredo, 2011).

Lo cierto es que cubrir las demandas del crecimiento previsto de la población y "sacar de la pobreza al mundo en desarrollo», sin poner en peligro los actuales niveles de vida de los países más desarrollados requeriría un enorme incremento de recursos energéticos. Y el escenario de un "crecimiento sostenible de recursos energéticos» es muy incierto. Más aún, la naturaleza compleja y no-lineal de la economía global plantea la posibilidad de que la escasez de energía desencadene grandes trastornos socioeconómicos (Brown et al., 2011).

La pregunta clave es cuántos de los valores de los consumidores con el nivel de vida del Primer Mundo puede conservar la población de los países ricos. Es patente la actual imposibilidad política de proponer a los ciudadanos del Primer Mundo que reduzcan su presión sobre el planeta. Pero «la alternativa de seguir manteniendo su impacto actual es aún más impracticable» (Diamond, 2007: 679). Ese es el gran problema: muchas preferencias, que en los países ricos ya están cubiertas por el sistema para una franja muy amplia de la sociedad, no se pueden reclamar como derechos porque no se pueden universalizar. Esto significa que «la transformación del sistema socioeconómico implica reducciones de niveles de seguridad y bienestar que son mayoritariamente consideradas conquistas sociales irrenunciables» (Martínez y Galante, 2011: 59). Todo parece apuntar a esta problemática conclusión, con la que Antonio Estevan terminaba su última reflexión sobre la riqueza y el poder: «El deterioro ecológico no se puede frenar sin limitar el crecimiento cuantitativo en los países sobredesarrollados. Esta tesis, nada nueva, sigue siendo incontestable, más allá de la propaganda desarrollista en la que siguen ancladas las instituciones» (Estevan, 2007: 20). 


\section{Consideraciones finales}

Asistimos a un proceso indiscutible de profundo deterioro ecológico, combinado con el comienzo de una crisis social y económica que se anuncia larga y de final muy incierto. Paso a paso, se confirman los augurios sobre la orientación de las dinámicas globales que empezaron a concretarse en los años setenta. Desde entonces, han estado parcialmente enmascarados por tres décadas de combustibles fósiles baratos y eso, unido a errores y exageraciones de las predicciones, ha justificado descalificaciones poco matizadas. La realidad es que, en el lado del pensamiento crítico, por contradictorios que puedan ser los enfoques esencialista-realista y constructivista en sus métodos y supuestos básicos, ambos coinciden en el diagnóstico de la situación actual: la sociedad del riesgo y de la crisis global. Para uno, son los peligros (los escenarios del desastre total) de la sociedad del riesgo global los que constituyen el centro principal de atención; para el otro, son las oportunidades, los contextos en los que actúan los actores.

La crisis energética, el cambio climático y el deterioro ecológico global están íntimamente relacionados. Desde importantes instancias de poder global, aunque no desde todas, se habla de uno de sus vértices, el cambio climático y sus consecuencias, pero se ignora casi totalmente hasta el presente, la más inminente crisis energética global y el declive ecológico, que también está en marcha. Es significativo constatar esta tendencia, cuando para el actual capitalismo global el declive energético es un problema mayor a corto plazo que el cambio climático, cuyas consecuencias son todavía limitadas, a pesar de su gravedad, puesto que todavía no afectan a las dinámicas centrales de la expansión y concentración del capital, aunque lo harán en el medio y largo plazo.

Pese a que el optimismo tecnológico sigue constituyendo el núcleo del pensamiento neoliberal, el complejo científico-técnico es visto cada vez con mayor claridad como parte esencial del problema, no de la solución. Como dice Horacio Capel: «Seguramente no necesitamos de más estudios científicos, aunque sean útiles todos los que se realicen. Lo que se necesita es una nueva actitud que reconozca que no basta simplemente el conocimiento científico. Es decir, un desplazamiento desde la geografía, la ecología o la economía hacia la geografía política, la ecología política y la economía política, por citar solo algunas ramas del conocimiento. $\mathrm{O}$, mejor aún, simplemente a la política» (Capel, 2003).

El tema central todavía no abordado políticamente, de una manera explícita, es que el deterioro ecológico no se puede frenar sin limitar el crecimiento cuantitativo en los países sobredesarrollados; que esto implica reducciones de niveles de seguridad y bienestar que son mayoritariamente considerados conquistas sociales irrenunciables, en sociedades que, aunque sobredesarrolladas, son profunda y crecientemente desiguales. La necesidad más urgente, a la que el pensamiento geográfico crítico tiene que contribuir, es aportar luz sobre quién va a conducir, quién va a gobernar (más allá de las élites, los poderes reales y sus representantes políticos que ya lo están haciendo) el proceso de decrecimiento real que ya ha comenzado y que no va a terminar con una vuelta a la situación 
de hace diez años de una manera estable; quién va a controlar la distribución espacial y el ritmo temporal del proceso; quién va a decidir y a favor de quién la naturaleza en la que queremos o podemos habitar.

\section{Bibliografía}

BeCK, Ulrich (1999). La sociedad del riesgo global. Madrid: Siglo XXI, 2002.

Boulding, Kenneth (1989). «La economía futura de la tierra como navío espacial». En: DaLY, H. (ed.). Economía, ecología y ética: Ensayos hacia una economía en estado estacionario. México: Fondo de Cultura Económica, 262-275. Edición original: «The Economics of Coming Spaceship Earth». En: Environmental Quality in a Growing Economy. Baltimore: John Hopkins Press, 1966, 3-19.

Brown, James H. (2011). «Energetic Limits to Growth». Bioscience, 61 (1), enero, 19-26.

CAPEL, Horacio (2003). «La geografía y los dos coloquios sobre la incidencia del hombre en la faz de la tierra». Biblio 3W: Revista Bibliográfica de Geografia y Ciencias Sociales [en línea], VIII, 459. <http://www.ub.edu/geocrit/b3w-459.htm> [Consulta: 15 desembre 2011].

Caravaca Barroso, Inmaculada y Zoido Naranjo, Florencio (coords.) (2006). Andalucía. Segundo Informe de Desarrollo Territorial. Sevilla: Fundación Sevilla Endesa; Universidad de Sevilla; Consejería de Innovación, Ciencia y Empresa de la Junta de Andalucía.

CARPINTERo, Óscar (2005). El metabolismo de la economía española: Recursos naturales y huella ecológica (1955-2000). Lanzarote: Fundación César Manrique.

Carrasco Bengoa, Cristina (2001). «La sostenibilidad de la vida humana: ¿Un asunto de mujeres?». Mientras Tanto, número dedicado a «Tiempo, sociedad y vida cotidiana», 82, 43-70.

Davis, Mike (2007). Planeta de ciudades. Madrid: Foca.

DALY, Herman E. (1989). «Introducción a la economía en estado estacionario». En: Daly, H. E. (comp.). Economía, ecología, ética: Ensayos hacia una economía en estado estacionario. México, D.F.: Fondo de Cultura Económica, 11- 43.

- (1997). Beyond Growth: The Economics of Sustainable Development. Boston: Beacon.

- (1999). «How long can neoclassical economists ignore the contribution of Georgescu-Roegen?». En: MaYumi, K. y Gowdy, J. M. Bioeconomics and Sustainability: Essays in Honor of Nicholas Georgescu-Roegen. Cheltenha, UK; Northampton, USA: Edward Elgar, 13-24.

Diamond, Jared (2007). Colapso. Por qué unas sociedades perduran y otras desaparecen (4a ed.). Barcelona: Debate.

Estevan Estevan, Antonio (2007). Riqueza, fortuna y poder. Málaga: Ediciones del Genal.

Estevan, Antonio (2008). Herencias y problemas de la política hidráulica española. Bilbao: Bakeaz.

Estevan, Antonio y Sanz, Alfonso (1996). Hacia la reconversión ecológica del transporte en España. Madrid: Bakeaz-Los Libros de la Catarata.

Fernández Durán, Ramón (2011). La Quiebra del Capitalismo Global: 2000-2030: Preparándonos para el comienzo del colapso de la Civilización Industrial. Madrid: Libros en Acción-Virus Editorial-Baladre. 
Georgescu-Roegen, Nocholas (1982). «La dégradation entropique et la destinée prométhéenne de la technologie humaine». Entropie, número extraordinario sobre "Thermodynamique et sciences de l'homme», 76-86.

Gleick, Peter H. y Palianappan, Meena (2011). «Peak Water Limits to Freshwater Withdrawal and Use». Proceedings of National Academy of Science, 107 (25), 11155-11162.

Gorz, André (1995). Capitalismo, Socialismo, Ecología. Madrid: Ediciones Hoac.

Greer, John M. (2008). The Long Descent: A user's Guide to the End of Industrial Age. Gabriola Island (Canada): New Society Publishers.

- (2009). The Ecotechnic Future: Envisioning a post-peak world. Gabriola Island (Canada): New Society Publishers.

Griffith-Jones, Stephany; Ocampo, Jose A. y Stiglitz, Joseph E. (eds.) (2010). Time for a Visible Hand: Lessons from the 2008 World Financial Crisis, Initiative for Policy Dialogue Series. Oxford: Oxford University Press.

Grinevald, Jacques (1979). Demain la décroissance. Lausana: Pierre-Marcel Favre.

Hamilton, Clive y Denniss, Richard (2005). Affluenza: When Too Much is Never Enough. Crows Nest (Australia): Allen \& Unwin.

Heinberg, Richard (2011). The End of Growth: Adapting to our new economic reality. Gabriola Island, Canadá: New Society Publishers.

- (2012). "China's Role in a World of Scarce Resources». Solutions. For a sustainable and desirable future [en línea], 3 (1), 16 de enero. <http://www.thesolutionsjournal. $\mathrm{com} /$ print/1036>.

Herrero, Yago (2010). "Vivir bien con menos; ajustarse a los límites físicos con criterios de justicia». Viento Sur, 108, 27-36.

Illich, Ivan (1978). La convivencialidad [en línea]. <http://habitat.aq.upm.es/boletin/ n26/aiill.html> [Consulta: 15 desembre 2011].

InFORME BRUndTLAND (1987). Our common future. Oxford: Oxford University Press. Versión española: Nuestro futuro común. Madrid: Alianza, 1988.

Jackson, Tim (2009). Prosperity Without Growth: Economics for a Finite Planet. Londres: Routledge.

Krugmann, Paul (2009). The Return of Depression Economics and the Crisis of 2008. Nueva York: WWNorton \& Company.

Latouche, Serge (2006). Le pari de la décroissance. París: Fayard.

LAtour, Bruno (1993). We have never been modern. Londres: Harvester Wheatsheaf.

Lomborg, Bjorn (2003). El ecologista escéptico. Madrid: Espasa Calpe.

Mander, J. (2007). Manifiesto sobre transiciones económicas globales. Madrid: CIPEcosocial.

Martínez, l. y Galante, CH. (2011). «Un término inconveniente». Viento Sur, 118, 54-61.

Martínez Alier, Joan (1992). De la economía ecológica al ecologismo popular. Barcelona: Icaria.

- (2009). «Socially Sustainable Economic Degrowth». Development and Change, 40 (6), 1099-1119.

Meadows, D. H.; Meadows, D. L. y Randers, J. (1991). Beyond the limits: Global collapse or a sustainable future. Londres: Earthscan. Versión española: Más allá de los límites del crecimiento. Madrid: El País y Aguilar, 1992.

MÉndez, Ricardo (2008). "Globalización y organización espacial de la actividad económica». En: Romero, J. (coord.). Geografía humana: Procesos, riesgos e incertidumbre en un mundo globalizado (3a imp.). Barcelona: Ariel, 221-273. 
Morin, Edgar (2010). «Elogio de la metamorfosis». El Pais, 17 de enero.

- (2011). La Vía. Para el futuro de la humanidad. Barcelona: Paidós.

Moral Espín, Lucía del y Coronado, M. V. (2010). «AAtención cuidados!: Qué aporta y recuerda el feminismo a las perspectivas decrecentistas». En: Taller decrecimiento y género, Jornadas sobre Decrecimiento ¿Decreces o enriqueces? Sevilla, 13 de marzo. Sevilla: El Quinto Tomate y Ecologistas en Acción.

Moral Ituarte, Leandro del y Pedregal Mateos, Belén (2005). «Nuevos planteamientos científicos y participación ciudadana en la resolución de conflictos ambientales». Documents d'Anàlisi Geogràfica, 41, 121-134.

Morton, Timothy (2007), Ecology without Nature. Rethinking Environmental Aesthetics. MA y Londres: Harvard University Press.

Naredo, José Manuel (1987). La economía en evolución: Historia y perspectivas de las categorías básicas del pensamiento económico (3a ed.). Madrid: Siglo XXI de España, 2003.

- (2010). Raíces económicas del deterioro ecológico y social: Más allá de los dogmas (2a ed. actualizada). Madrid: Siglo XXI.

- (2011). "Reflexiones sobre la bandera del decrecimiento». Viento Sur, 118, septiembre, 23-35.

Naredo Pérez, José Manuel y Valero Capilla, Antonio (dirs.) (1999). Desarrollo económico y deterioro ecológico. Madrid: Fundación Argentaria.

Navarro, Vicent; Torres López, Juan y Garzón Espinosa, A. (2011). Hay alternativas: Propuestas para crear empleo y bienestar social en España. Madrid: Sequitur.

Nogué, Joan y Romero, Joan (2006). «Otras geografías, otros tiempos: Nuevas y viejas preguntas, viejas y nuevas respuestas». En: Nogué, J. y Romero, J. Las otras geografias. Valencia: Tirant lo Blanch, 15-50.

Ojeda Rivera, Juan F. (1999). «Naturaleza y desarrollo: Cambio en la consideración política de lo ambiental durante la segunda mitad del siglo xx». Papeles de Geografía. Universidad de Murcia, 103-118.

- (2011). «Inteligencia compartida y resiliencia social: De cómo salir bien parados en tiempos de crisis». Presentación en mesa redonda de Convención sobre Cambio Climático. Sevilla: Universidad Pablo de Olavide, noviembre de 2011.

Pita López, María Fernanda y Pedregal Mateos, Belén (coords.) (2011). Tercer Informe de Desarrollo Territorial de Andalucía. Sevilla: Secretariado de Publicaciones de la Universidad de Sevilla.

PNUMA (2011). Convenio de Basilea, sobre el control de los movimientos transfronterizos de los desechos peligrosos y su eliminación [en línea]. <http://www.basel.int/ Portals/4/Basel\%20Convention/docs/text/BaselConventionText-s.pdf> [Consulta: 12 diciembre 2011].

Prats Palazuelo, Fernando (2009). "Ciudades y cambio global en España». En $7^{\circ}$ concurso de Naciones Unidas sobre Buenas Prácticas para mejorar las condiciones de vida. Madrid: Ministerio de la Vivienda, 12-15.

Riechmann, Jorge (2004). Gente que no quiere viajar a Marte: Ensayos sobre ecología, ética y autolimitación. Madrid: Catarata.

- (2007). "Ahora menos que nunca podemos separar el problema ecológico de la cuestión social». Centro de Investigación para la Paz (CIP-Ecosocial) - Boletín ECOS, 1, enero.

Roberts, Paul (2004) (2010). El fin del petróleo. Madrid: Biblioteca de Pensamiento Crítico, Público. 
Schneider, F.; Kallis, Giorgos; Martínez-Alier, Joan (2010). «Crisis or opportunity?: Economic degrowth for social equity and ecological sustainability. Introduction to this special issue». Journal of Cleaner Production, 18, 511-518.

Schumacher, Ernst Friedrich (1973). Small is Beautiful. Londres: Blond and Briggs.

Swyngedouw, Erik (1999). "Hybrid Waters: On Water, Nature and Society». En: Conference sustainability, Risk and Nature: The Political Ecology of Water in Advanced Societies. Oxford: School of Geography and the Oxford Centre for Water Research, 2-11.

- (2011). «iLa naturaleza no existe!: La sostenibilidad como síntoma de una planificación despolitizada». Urban, NS01, 41-66.

Tainter, Joseph A. (1988). The Collapse of Complex Societies. Nueva York y Cambridge: Cambridge University Press, 2003.

Trainer, T. (2011). :Entienden bien sus defensores las implicaciones politicas radicales de una economía de crecimiento cero? [en línea]. <http://www.sinpermiso.info/articulos/ficheros/decre.pdf> [Consulta: 15 diciembre 2011].

Villalba, U. (2008). «El concepto de deuda ecológica y algunos ejemplos en Ecuador». En: XI Jornadas de Economía Crítica [en línea]. Bilbao, marzo. <http://www. ucm.es/info/ec/ecocri/eus/Villalba_Egiluz.pdf> [Consulta: 15 diciembre 2011].

Zoido Naranjo, Florencio (coord.) (2001). Informe de Desarrollo Territorial de Andalucía (IDTA). Sevilla: Fundación Sevillana de Electricidad; Universidad de Sevilla; La General-Caja de Granada. 